\title{
Değer bazlı performans ölçümüne katkı sunan üç ölçüm aracı: Performans ölçüm matrisi, performans piramidi ve Cambridge performans ölçüm çerçevesi
}

\author{
Hakan CAVLAK ${ }^{a}$ \\ a Arş. Gör. Dr., Ardahan Üniversitesi IïBF Iş̧letme Bölümü, hakancavlak@ardahan.edu.tr, ORCID: 0000-0002-5891-7722
}

MAKALE BILGILERi

Araştırma Makalesi Geliş Tarihi 16 Ekim 2020 Revizyon 31 Ekim 2020

Kabul tarihi 7 Kasım 2020

\section{Özet}

İ̧letme yöneticileri ve paydaşları, işletme ile ilgili aldıkları kararlarda referans noktası olarak performans ölçümü sonucunda ortaya çıkan bilgileri kullanmaktadırlar. İ̧̧letme yönetiminde kontrol görevini yürüten performans ölçümü geçmişten günümüze kadar birçok değişim ve gelişim göstermiştir. İşletmeler, başlangıçta basit şekilde hesaplanan, sadece finansal verilere dayalı, geçmişe yönelik bilgiler sunan geleneksel performans ölçümünü kullandılar. Daha sonraki dönemde ise paydaşların ve toplumsal taleplerin farklılaşması, teknolojik gelişim gibi muhtelif etkenler doğrultusunda geliştirilen, finansal olmayan verileri de içeren ve geleneksel yöntemlere göre daha karmaşık şekilde hesaplanan çok boyutlu değer bazlı performans ölçüm yöntemleri kullanılmaya başlanmıştır. Bu çerçevede birçok çalışma gerçekleştirilmiş ve ortaya çıkan yöntemler uygulama alanı bulmuştur. Bu çalışmada, değer bazlı performans ölçüm yöntemleri içerisinde yer alan ancak fazla bir uygulama alanı bulamayan Performans Ölçüm Matrisi, Performans Piramidi ve Cambridge Performans Ölçüm Çerçevesi incelenmiştir. Bu yöntemlerin ortak noktası, kendinden sonra oluşturulan değer bazlı performans ölçüm yöntemlerine fikirsel olarak katkıda bulunmalarıdır. Bu katkılar; performans ölçüm matrisinde, çok boyutluluk ve denge; performans piramidinde, ölçüm araçlarına bütünsel bir bakış açısı sunması, Cambridge performans ölçüm çerçevesinde ise ölçüm yöntemlerinin değerlendirilmesi şeklinde gerçekleşmiştir. İlgili yöntemlerin en temel ortak noktası, bu yöntemlerin sunduğu anlayışa getirilen eleştirilerin kapsamlı olarak değerlendirilmesi ile farklı değer bazlı performans ölçüm yöntemlerinin ortaya çıkmış olmasıdır. Çalışmanın bu doğrultuda ilgililere konu hakkında genel bir bakış açısı sunması beklenmektedir.

Anahtar Kelimeler: Değer Bazlı Performans Ölçümü, Performans Ölçüm Matrisi, Performans Piramidi, Cambridge Performans Ölçüm Çerçevesi.

Three measurement tools contributing to value-based performance measurement: Performance measurement matrix, performance pyramid and Cambridge performance measurement framework

\section{ARTICLE INFO}

Research Article

Received 16 October 2020

Received in revised form

31 October 2020

Accepted 7 November

2020

\section{Abstract}

Business managers and stakeholders use the information obtained as a result of performance measurement as a reference point in the decisions they take regarding the business. Performance measurement that carries out its control function in business management has undergone many changes and developments from past to present. Initially, organizations used traditional performance measurement that was strictly measured, based only on financial data, providing historical information. In the following period, value-based performance measurement methods, which were developed in line with various factors such as the differentiation of stakeholders and social demands, technological development, including non-financial data and calculated more complex than traditional methods, began to be used. Many studies have been carried out within this framework. Value-based performance measurement methods that emerged as a result of these studies were applied by the businesses. In this study, Performance Measurement Matrix, Performance Pyramid and Cambridge Performance Measurement Framework, which are among the value-based performance measurement methods but not used in practice, have been examined. The common point of these methods is that they contribute intellectually to the value-based performance measurement methods created after them. These contributions; multidimensionality and balance in performance measurement matrix; in the performance pyramid, it presented a holistic perspective to measurement tools, and in the Cambridge performance measurement framework, it was realized as an evaluation of measurement methods. In this context, this study is expected to provide a general perspective to those concerned.

Key Words: Value-based Performance Measurement, Performance Measurement Matrix, Performance Pyramid, Cambridge Performance Measurement Framework.

\section{Giriş}

Küreselleşme olgusu başta olmak üzere teknolojik gelişmeler, ticari yaşamın farklılaşması vb. faktörler her alanda olduğu gibi işletmeler adına da hızlı değişmelerin yaşanmasına neden olmuştur. Söz konusu değişim, işletmelerin tüm unsurları üzerinde bir etkiye sahip olmakla birlikte performans ölçümünde de etkisini göstermiştir (U. Bititci, Garengo, Dörfler, \& Nudurupati, 2012). İşletme kaynaklarının etkin şekilde kullanılması gereken yoğun rekabet ortamında işletmeler, temel işletme yönetimi araçları olan kontrol ve karar mekanizmalarının kullanımını ve belirledikleri hedeflere ulaşma derecelerini görebilmek adına işletme performansının doğru ve gerçekçi bir şekilde ölçmek zorundadırlar. Bu zorunluluk ayrıca işletmenin gelecekte yer alacağı konumu tayin etme, bu çerçevede işletme çalışanları başta olmak üzere tüm unsurları yönlendirme ve hem işletmeler hem de işletme paydaşları için önemli bir karar destek aracı sağlanması açısından önem arz etmektedir (Çakır \& Perçin, 2013; Martin, 1997; Robson, 2004; Whiting, 1986).

Performans ölçümü, bir işletmenin faaliyet alanını oluşturan farklı süreçlerin yolunda gidip gitmediğini görmek için önemli bir araçtır. Ayrıca performans ölçümü, rekabet avantajı ve farklılaşma elde etmek isteyen işletmeler tarafından giderek daha fazla kullanılmaktadır (Alfaro, Ortiz, \& Poler, 2007). Performans değerlendirmesi, genel olarak işletmenin belirli bir faaliyet dönemine ilişkin bütünsel bir bakış açısı sağlamak ile birlikte bu bütünün oluşmasına katkıda bulunan 
işletme çalışanlarının bireysel ve takım olarak da değerlendirilmesini içermektedir. Ancak asıl amaç organizasyonun, kurumun ya da işletmenin performansının ölçülmesidir (Işı̆̌ıçok, 2008).

Güçı̈ bir performans yönetim sistemi ile bu sürecin etkinliği, işletmenin başarısı ve başarısızlığı arasındaki farkı belirlemektedir. Bu tespit, performans yönetim sistemi ile işletmelerin hedeflerine ne kadar ulaştıklarını izleyebilmelerinden, karar vermelerini kolaylaştırabilmelerinden, çalışanlarını belirli amaç doğrultusunda daha iyi yönlendirebilmelerinden kaynaklanmaktadır (Yüreğir \& Nakıboğlu, 2007). Performans ölçümü, işletmelerde performans ölçüm/yönetim sürecinin bir parçası olarak yer almaktadır ve bu yapı içindeki görevini finansal veya finansal olmayan muhtelif performans ölçütleri vasıtası ile yerine getirerek işletme faaliyetlerinin etkinliğini ve verimliliğini belirlemektedir (Bourne, Neely, Mills, \& Platts, 2003; Neely, Gregory, \& Platts, 1995).

Performans ölçümünün temel amacı, işletmenin kurumsal başarı/başarııızlığını ya da belirlenen hedeflerin karşılanıp/karşılanmadığını ölçümlemek olmakla birlikte işletme ve paydaşlarının alacakları kararlarda destekleyici veya değiştirici bir rol oynamak, yapılacak iyileştirmeler için tespitte bulunmak, stratejik kararlara temel oluşturmak, hissedar değerini maksimize etmek gibi amaçlarda performans ölçümünün hedefleri arasında yer almaktadır (Daft, 2010; Erasmus, 2008; Parker, 2000; van Veen-Dirks, 2010)

Başlangıçta muhasebe temelli başlayan performans ölçümü, 19. yüzyıla kadar uzanan bir tarihe sahiptir. Günümüze kadar olan süreçte ise performans ölçümü, çeşitli açılardan değişim ve gelişim göstermiştir. Bu değişim ve gelişimde öne çıkan hususlar; sadece performans ölçümünün yapııldı̆̆ı bir aşamadan performans yönetiminin ve sisteminin kurulduğu bir aşamaya geçilmesi, tek boyutlu ve finansal bilgilere dayalı performans ölçümünden çok boyutlu, dengeli ve finansal olmayan bilgiyi de içeren performans ölçümüne geçilmesi, içsel çevreyi ilgilendiren işlevsel ve etkileşimsel bir nitelikten dı̧̧ çevreyi de içine alan sistemsel ve ilişkisel nitelik ve perspektife dönülmesi, geçmişe dayalı bilgi ile kısa vadeli çıkarımlardan bugünü ve geleceği de kapsayan bilgi ile kısa, orta ve uzun vadeli çıkarımların yapılabildiği bir yapının oluşması, sadece yönetici ve hissedarları ilgilendiren sorumluluk düzeyinden işletmenin tüm paydaşlarını sorumlu tutan bir süreç inşa edilmesi, alınan kararlara kolaylaştırıcı ve destekleyici katkıdan bunlara ek olarak kararları etkileyici ve değiştirici katkı sağlanmasıdır. Iffade edilen tüm bu değişim ve gelişim, muhtelif yazarlar tarafından yapılan ve ikili sınıflandırma olarak ifade edilen geleneksel performans ölçümünden (1980 öncesi dönem) değer bazlı performans ölçümüne (1980 sonrası dönem) geçişte de (bkz. Tablo 1) kendini göstermektedir (Ghalayini, Noble, \& Crowe, 1997; Yadav \& Sagar, 2013; Yüreğir \& Nakıboğlu, 2007; Zsido, 2015).

Tablo 1. Geleneksel ve değer bazlı performans ölçümünün özellikleri

\begin{tabular}{|c|c|c|}
\hline Özellik & Geleneksel Performans Ölçümü & Değer Bazlı Performans Ölçümü \\
\hline Veri & Sayısal ve Basit Veri & Sayısal, Sözel ve Büyük Veri \\
\hline Kaynak & Finansal Tablolar, Finansal İçerikli Raporlar & Finansal Tablolar, Her Çeşit Raporlar \\
\hline Kapsam & Finansal İşlemler, Tek Boyutlu & Finansal ve Finansal Olmayan İşlemler, Çok Boyutlu \\
\hline Hesaplama & Basit & Karmaşık \\
\hline Illgili Paydaşlar & İç Paydaşlar (Özellikle Hissedarlar) & İç ve Dış Paydaşların Tümü \\
\hline Hedef & Geçmiş Sonuçları Analiz Etmek & $\begin{array}{l}\text { Geçmiş Sonuçları Analiz Etmek ve } \\
\text { Geleceğe Işı Tutmak }\end{array}$ \\
\hline Fayda & Kısa ve Orta Vadeli & Kısa, Orta ve Uzun Vadeli \\
\hline Ilgili Departman & Muhasebe ve Finans & İşletmedeki Tüm Departmanlar \\
\hline
\end{tabular}

Kaynak: Cavlak, H. (2019).

Tablo 1'den görüldüğü üzere işletmeler, 1980'lere kadar ağırlıklı olarak faaliyetlerini izlemek, kontrol etmek ve iyileştirmek adına muhasebe temelli geleneksel performans ölçümü gerçekleştirmişlerdir. Ancak bu ölçümleme, sadece finansal unsurları içermesi ve ağırlıklı olarak geçmişi analiz etmesinden dolayı özellikle işletme paydaşları adına yetersiz görülmeye ve çalışanlar, müşteriler, çevre gibi işletmede değer yaratan finansal olmayan unsurları da içeren çok boyutlu bir performans değerlendirmesi talep edilmeye başlanmıştır. 1980 sonrasındaki dönemde ise değişen teknoloji, ekonomik düzen, ticari hayat, çevresel ve yasal düzenlemeler ile paydaşların değişen talepleri gibi etmenler doğrultusunda performans ölçümü basit bir yapıdan daha kapsayıcı ve karmaşık bir yapıya doğru geçiş yapmıştır. Bu yapı, geleneksel performans ölçümlerinin sınırlarını zorlamış ve işletmeler, işletmedeki tüm departmanları ilgilendiren, finansal bilgiler yanında finansal olmayan bilgileri de içeren çok boyutlu ve değer bazlı performans ölçümleri geliştirmek durumunda kalmışlardır (U. Bititci vd., 2012; Bourne, Mills, Wilcox, Neely, \& Platts, 2000; Cavlak, 2019; Yüreğir \& Nakıboğlu, 2007). Değerli bazlı performans ölçümünün meydana çıkmasındaki etkenlerden biri de konu ile ilgili çalışmalar yürüten akademisyenler ile yatırımcılar başta olmak üzere işletme paydaşlarının tek boyutlu ve finansal ölçümlere dayanan geleneksel yaklaşım yerine finansal olmayan ölçümü de içeren, orta ve uzun vadeli fayda sağlayan çok boyutlu bir yaklaşımın işletmenin performansını ve değerini daha iyi yansıtacağını öngörmeleri olarak ifade edilmektedir (Burgess, Ong, \& Shaw, 2007; Franco-Santos, Lucianetti, \& Bourne, 2012).

Değer bazlı performans ölçümü, literatüre yeni bir anlayış getirmesinden dolayı "çağdaş performans ölçümü" ve "modern performans ölçümü", finansal olmayan bilgileri dikkate almasından dolayı "çok boyutlu performans ölçümü", "bütünleşik performans ölçümü" ve "entegre performans ölçümü" gibi isimlendirmeler ile de kullanılmaktadır.

Değer bazlı performans ölçümü, günümüzde işletmeler için kritik bir öneme sahiptir. William Edwards Deming'e atfedilen "Sonuçlara göre yönetim, dikiz aynasına bakarak araba kullanmak gibidir." ifadesi değer bazlı performans ölçümüne yüklenen önem için de yorumlanabilmektedir. Sadece işletmenin performansını geçmişe yönelik sonuçlar şeklinde gösteren ve finansal ağırlıklı bilgileri içeren geleneksel performans ölçümü ile işletmeyi yönetmek, dikiz aynasına bakarak araba kullanmaya benzetilmektedir. Dikiz aynası, işletmenin nerede olduğunu gösterir, ancak gelecekte nereye gideceğini ya da gidebileceğini göstermez. Bu sebeple de finansal bilgiler yanında finansal olmayan bilgileri de içeren çok boyutlu bir performans ölçümleme anlayışı önemlidir. Bu nokta da değer bazlı performans ölçümü öne çıkmaktadır. Diğer taraftan işletmelerinin nihai hedefinin artık sadece kâr (geleneksel performans ölçümünün bir göstergesi) etmek olmaması, sürdürülebilir kârlılı̆ın (değer bazlı performans ölçümünün bir göstergesi) daha önemli hale gelmesi, değer bazlı performans ölçümünün önemini göstermektedir (Koller, 1994; Otley, 2007).

Literatürde değer bazlı performans ölçümleri ile ilgili oluşturulan ve öne çıkan çalışmalar Tablo 2'de verilmektedir. Tabloda yer alan çalışmaların bazıları finansal unsurları da içeren ölçümler iken ağırlıkıı kısmı ise kalite, üretim ve benzeri unsurları ön plana çıkartan değer bazlı performans ölçümleridir.

Tablo 2. Değer bazlı performans ölçümü ile ilgili çalışmalar

\begin{tabular}{clc}
\hline Yıl & Performans Ölçümünü Adı & Ölçümü Geliştiren(ler) \\
\hline 1930 lar & Kumanda Paneli (Tableu de Bord) & Fransız Muhasebe Uzmanları \\
\hline 1951 & Deming Ödülü (Deming Prize) & Deming \\
\hline 1980 & Ekonomik Katma Değer (Economic Value Added) & Stern ve Stewart \\
\hline 1985 & Performans Kriteri Sistemi (Performance Criteria System) & Globerson \\
\hline 1987 & Malcolm Baldrige Ulusal Kalite Ödülleri (Malcolm Baldrige National Quality Award) & NIST \\
1988 & Faaliyet Tabanlı Maliyet / Faaliyet Tabanlı Yönetim & Cooper ve Kaplan \\
& (Activity Based Costing) / (Activity Based Management)
\end{tabular}




\begin{tabular}{|c|c|c|}
\hline 1989 & $\begin{array}{l}\text { Performans Ölçüm Matrisi / Destekleyici Performans Ölçütleri } \\
\text { (Performance Measurement Matrix) / (Supportive Performance Measures) }\end{array}$ & Keegan, Eiler ve Jones \\
\hline 1989 & $\begin{array}{l}\text { Stratejik Ölçüm Analizi ve Raporlama Tekniği } \\
\text { (Strategic Measurement Analysis and Reporting Technique) }\end{array}$ & Cross ve Lynch \\
\hline 1989 & Sink ve Tutle Performans Ölçüm Sistemi (Sink and Tutle Performance Measurement System) & Sink ve Tutle \\
\hline 1989 & $\begin{array}{l}\text { Dünya Standartlarında Üretim için Performans Ölçümü } \\
\text { (Performance Measurement for World Class Manufacturing) }\end{array}$ & Maskell \\
\hline 1990 & Müşteri Değer Analizi (Customer Value Analysis) & Gale \\
\hline 1990 & Performans Ölçüm Anketi (Performance Measurement Questionnaire) & Dixon, Nanni and Vollmann \\
\hline 1990 & $\begin{array}{l}\text { Verimlilik Ölçme ve Geliştirme Sistemi } \\
\text { (Productivity Measurement and Enhancement System) }\end{array}$ & Pritchard \\
\hline 1991 & Performans Piramidi (Performance Pyramid) & Cross ve Lynch \\
\hline 1991 & Skandia Kılavuzu (Skandia Business Navigator) & Edvinsson \\
\hline 1991 & Sonuçlar ve Belirleyiciler Çerçevesi (Results and Determinants Framework) & $\begin{array}{l}\text { Fitzgerald, Johnston, Brignall, } \\
\text { Silvestro ve Voss }\end{array}$ \\
\hline 1992 & Dengeli Performans Karnesi (Balanced Scorecard) & Kaplan ve Norton \\
\hline 1992 & $\begin{array}{l}\text { Avrupa Kalite Yönetim Vakfı Mükemmellik Modeli } \\
\text { (European Foundation for Quality Management Excellence Model) }\end{array}$ & EFQM \\
\hline 1992 & TOPP Performans Ölçüm Sistemi (TOPP Performance Measurement System) & SINTEF \\
\hline 1994 & Hizmet-Kâr Zinciri (Service-Profit Chain) & $\begin{array}{l}\text { Heskett, Jones, Loveman, } \\
\text { Sasser ve Schlesinger }\end{array}$ \\
\hline 1995 & Kalite Yaklaşımı Getirisi (Return on Quality Approach) & Rust, Zahorik ve Keiningham \\
\hline 1996 & Kuantum Performans Ölçüm Modeli (Quantum Performance Measurement Model) & $\begin{array}{l}\text { Steven M. Hronec, Arthur } \\
\text { Andersen ve Co. }\end{array}$ \\
\hline 1996 & $\begin{array}{l}\text { Cambridge Performans Ölçüm Çerçevesi } \\
\text { (Cambridge Performance Measurement Framework) }\end{array}$ & $\begin{array}{l}\text { Neely, Mills, Gregory, } \\
\text { Richards, Platts ve Bourne }\end{array}$ \\
\hline 1996 & Tutarlı Performans Ölçümü Sistemi (Consistent Performance Measurement System) & Flapper, Fortuin ve Stoop \\
\hline 1996 & AMBITE Performans Ölçüm Kübü (AMBITE Performance Measurement Cube) & Bradley \\
\hline 1997 & Bütünleşik Performans Ölçüm Sistemi (Integrated Performance Measurement System) & Bititci, Turner ve Begemann \\
\hline 1997 & $\begin{array}{l}\text { Bütünleşik Dinamik Performans Ölçüm Sistemi } \\
\text { (Integrated Dynamic Performance Measurement System) }\end{array}$ & Ghalayini, Noble ve Crowe \\
\hline 1997 & Performansın Üç R'si (Three Rs of Performance) & Montague \\
\hline 1998 & Karşılaştırmalı İşletme Performans Karnesi (Comparative Business Scorecard) & Kanji \\
\hline 1998 & $\begin{array}{l}\text { Bütünleşik Performans Ölçüm Çerçevesi } \\
\text { (Integrated Performance Measurement Framework) }\end{array}$ & Medori ve Steeple \\
\hline 1999 & Süreç Performansı Ölçüm Sistemi (Process Performance Measurement System) & Kueng ve Krahn \\
\hline 2000 & Dinamik Performans Ölçüm Sistemi (Dynamic Performance Measurement System) & Bititci, Turner ve Begemann \\
\hline 2000 & $\begin{array}{l}\text { Performans Ölçüm Sistemi için Sayısal Bir Model } \\
\text { (Quantitative Models for Performance Measurement Systems) }\end{array}$ & Suwignjo, Bititci ve Carrie \\
\hline 2000 & $\begin{array}{l}\text { [CSIRO] Organizasyonel Performans Ölçüm Sistemi } \\
\text { ([CSIRO]Organisational Performance Measurement System) }\end{array}$ & $\begin{array}{l}\text { Chennell, Dransfield, Field, } \\
\text { Fisher, Saunders \& Shaw }\end{array}$ \\
\hline 2001 & Performans Prizması (Performance Prism) & $\begin{array}{l}\text { Neely, Adams, Kennerley ve } \\
\text { Crowe }\end{array}$ \\
\hline 2001 & Faaliyet-Kazanç Bağlantı Modeli (Action-Profit Linkage Model) & Epstein ve Westbrook \\
\hline 2003 & $\begin{array}{l}\text { Dinamik Çok Boyutlu Performans Çerçevesi } \\
\text { (Dynamic Multi-Dimensional Performance Framework) }\end{array}$ & Maltz, Shenhar \& Reilly \\
\hline 2004 & Performans Planlama Değer Zinciri (The Performance Planning Value Chain) & Neely and Jarrar \\
\hline 2004 & $\begin{array}{l}\text { Maddi ve Maddi Olmayan Varlıkların Ekonomik Değeri } \\
\text { (Capability Economic Value of Intangible and Tangible Assets) }\end{array}$ & $\begin{array}{l}\text { Ratnatunga, Gray ve } \\
\text { Balachandran }\end{array}$ \\
\hline 2006 & $\begin{array}{l}\text { Performans, Geliştirme, Büyüme ve Kıyaslama Sistemi } \\
\text { (The Performance, Development, Growth Benchmarking System) }\end{array}$ & St-Pierre \& Delisle \\
\hline 2006 & Bütüncül Performans Yönetim Çerçevesi (Holistic Performance Management Framework) & $\begin{array}{l}\text { Andersen, Henriksen ve } \\
\text { Aarseth }\end{array}$ \\
\hline 2007 & Kullanılmayan Kapasite Ayrıştırma Çerçevesi (Unused Capacity Decomposition Framework) & Balachandran, Shu \& Suresh \\
\hline 2007 & Dönüşümsel Ölçüm (Transformational Measurement) & Spitzer \\
\hline 2008 & PMM Çerçevesi ve Ölçütleri için Referans Modeli & Taticchi \\
\hline
\end{tabular}




\begin{tabular}{ccc}
\hline & (Reference Model for PMM Framework and Measures) & \\
\hline 2009 & Performans Yönetim Sistemleri Çerçevesi (Performance Mangement Systems Framework) & Ferreira and Otley \\
\hline 2010 & Esnek Strateji Oyun Kartı (Flexible Strategy Game-card) & Sushil \\
\hline 2011 & $\begin{array}{l}\text { Sistem Dinamikleri Tabanlı Dengeli Performans Karnesi } \\
\text { (System Dynamics-based Balanced Scorecard) }\end{array}$ & Barnabè \\
\hline 2011 & Proaktif Dengeli Performans Karnesi (Proactive Balanced Scorecard) & Chytas, Glykas ve Valiris \\
\hline 2011 & Karma Performans Ölçüm Çerçevesi (Hybrid Performance Measurement Framework) & Fukushima ve Peirce \\
\hline 2011 & $\begin{array}{l}\text { Sürdürülebilirlik Performans Ölçüm Sistemi } \\
\text { (Sustainability Performance Measurement Systems) }\end{array}$ & Searcy \\
\hline
\end{tabular}

Kaynak: Cavlak, H. (2019).

1930'lu yıllarda Kumanda Paneli ile başladığı kabul edilen değer bazlı performans ölçümü, Tablo 2'de görüldüğü gibi zaman içinde birbirini etkileyen birçok çalışmaya konu olmuş ve bu çerçevede muhtelif değer bazlı performans ölçüm yöntemleri geliştirilmiştir. Bu çalışmada ise Tablo 2'de de yer alan ve pek fazla ön planda tutulmayan ancak kendinden sonra gelen birçok performans ölçüm yöntemine doğrudan ya da dolaylı olarak katkılar sağlayan üç yöntem (Performans Ölçüm Matrisi, Performans Piramidi, Cambridge Performans Ölçüm Çerçevesi) ele alınmaktadır. Çalışmanın konu hakkında çalışma yapacaklara değer bazlı performans ölçümünün gelişimi hakkında bilgi sunması ve ele alınan üç yönteme ilişkin genel bir çerçeve oluşturması amaçlanmaktadır.

\section{Performans Ölçüm Matrisi (Performance Measurement Matrix)}

Performansın farklı boyutlarını bütünleşik bir biçimde ele alan "Performans Ölçüm Matrisi", 1989 yılında Keegan, Eiler ve Jones tarafından ortaya konulmuştur (Striteska \& Spickova, 2012). Matris, bazı çalışmalarda "Destekleyici Performans Ölçütleri" (Supportive Performance Measures) olarak da adlandırılmaktadır (Pidun \& Felden, 2011).

Performans ölçüm matrisi, işletmelerin içsel çevresi yanında dışsal çevresini de kapsayan ve bunların işletmenin stratejisi ile birlikte paralel hareket etmesini öngören bir performans ölçüm yapısının gerekliliğinden hareket etmektedir. Bu nedenle de performans ölçüm matrisi, performansın birden çok boyutunu dikkate alan, değer bazlı ve dengeli bir ölçüm yaklaşımı olarak tanımlanmaktadır (Keegan, Eiler, \& Jones, 1989).

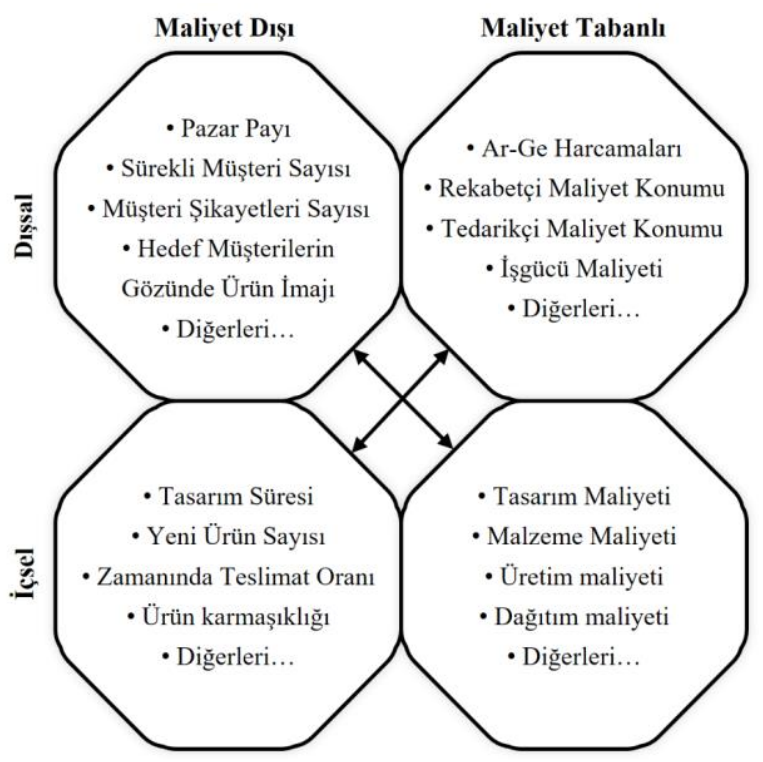

Şekil 1. Performans ölçüm matrisi / destekleyici performans ölçütleri Kaynak: Daniel P. Keegan, Robert G. Eiler ve Charles R. Jones. (1989).

Şekil 1'deki gibi şematize edilen performans ölçüm matrisi, performans göstergelerini "maliyet tabanlı" veya "maliyet dışı" ve "içsel" veya "dışsal" olarak sınıflandırmaktadır. Modelin anahtarı, performans göstergelerinin öncelikli olarak belirlenmesi (içsel-dışsal) ve daha sonrada ayrıştıııması (maliyet tabanlımaliyet dışı) yaklaşımını kullanmasından kaynaklanmaktadır. Ayrıca bu yaklaşım, söz konusu fonksiyonel sınıflandırmanın departmanların faaliyetlerini nasıl desteklediğini değerlendirmeyi de içermektedir (Watts \& McNair-Connolly, 2012).

Matrisin kapsadığı ana hususlar ve aşamalar ise şu şekilde özetlenmektedir (Keegan vd., 1989):

$\checkmark$ Ölçütler oluşturulmadan işletmenin stratejik hedefi netleştirilmeli.

$\checkmark$ Performans ölçütleri, işletmenin çok boyutlu çevresini kapsamalı.

$\checkmark$ Ölçütler, [2,2] matris șeklinde konumlandırılmalı.

$\checkmark$ Bu çerçevede dört alanda oluşturulan performans ölçütleri [içsel-dışsal, maliyet tabanlı-maliyetsiz] belirlenmeli ve bunlar arasında ilişki kurulmalı.

$\checkmark$ Ölçütler puanlandırılarak performansın ölçümü yapılmalı.

Görüldüğü gibi performans ölçüm matrisinin güçlü yönleri sadeliği ve bütünleşik yapısıdır (U. S. Bititci, 2015). Bununla birlikte matrisin eleştirilen en büyük yanı ise dengeli performans karnesi kadar performans boyutlarını iyi açıklamaması ve boyutlar arasındaki bağlantıyı net bir şekilde ortaya koymamasıdır. Bu nedenle de yapılan çoğu çalışma sonucunda matrisin güncellenmesi gerektiği ifade edilmektedir (Neely vd., 2000). Bu tespit doğrultusunda ilgili çalışmanın kabul gören tarafları ele alınarak ve geliştirilerek daha sonraki yıllarda oluşturulan değer bazlı performans ölçüm araçlarının bazılarına temel teşkil ettiği ifade edilebilir.

\section{Performans Piramidi (Performance Pyramid)}

Değer bazlı bir performans ölçütü olan "Stratejik Ölçüm Analizi ve Raporlama Tekniği" (Strategic Measurement Analysis and Reporting Technique - SMART), 1989 yllında Croos ve Lynch tarafından aşağıda yer alan durumlar sonucunda geliştirilmiştir (Cross \& Lynch, 1988):

$\checkmark$ Geleneksel performans ölçütlerinin yetersizliği,

$\checkmark$ işletme faaliyetlerinin stratejik hedeflere bağlanmaması,

$\checkmark$ Üretimin stratejik misyon içindeki işlevinin tanımlanmaması,

$\checkmark$ Finansal olmayan bilgilerin analiz edilebilecek şekilde raporlanmaması,

$\checkmark$ Müşterinin talepleri çerçevesinde işletme faaliyetlerinin güncellenmemesi. 
Bu teknik ile işletme başarısını tanımlamak ve sürdürülebilir kılmak adına performans göstergeleri olan bir yönetim kontrol sisteminin tasarlanması amaçlanmıştır (Pun \& White, 2005). Bu çerçevede; stratejik öneme sahip göstergeler netleştirilmiş, departmanlar arasında uzlaşma sağlanmış ve ilgili kişilerin işletmenin sürdürülebilirliği konusunda raporlar hazırlamasını sağlayacak ölçütler geliştirilmiştir (Cross \& Lynch, 1988).

Bir sonraki aşamada ise Şekil 2'de görülen ve SMART kontrol sisteminin yapısal çerçevesini dört seviyeli bir hedefler-ölçütler piramidi ile temsil eden "Performans Piramidi" ("SMART Performans Primadi" olarak da ifade edilmektedir) inşa edilmiştir (Ghalayini \& Noble, 1996). Bu piramit temel olarak, işletmenin stratejileri ve faaliyetleri arasında etkili bir bağlantı kurulmasını hedeflemektedir (Cross \& Lynch, 1988).

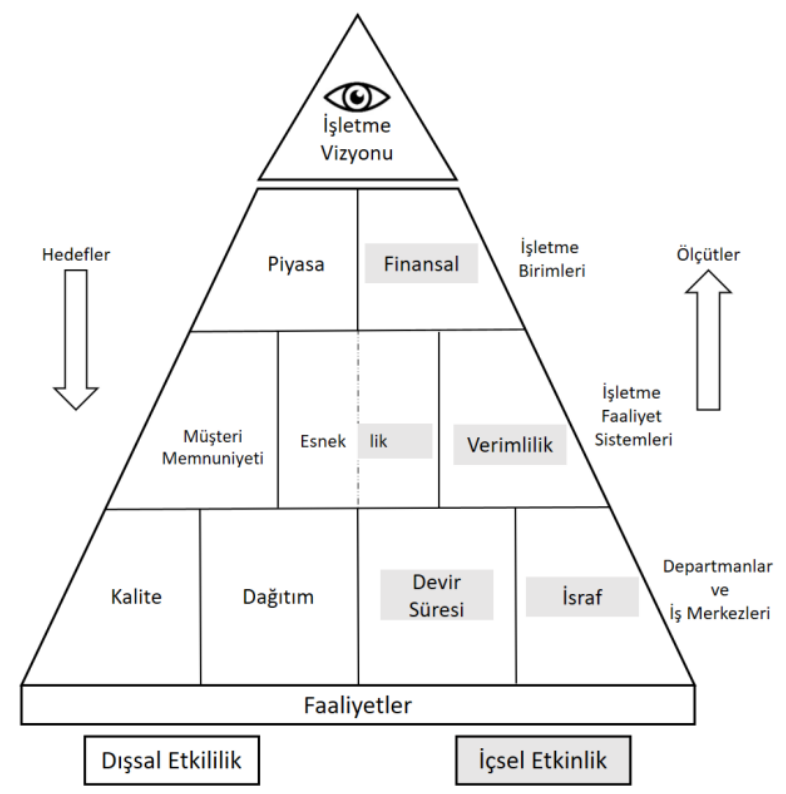

Şekil 2. Performans piramidi

Kaynak: Richard L. Lynch ve Kelvin F. Cross. (1992).

Performans piramidine göre performans ölçüm araçlarının önemli gerekliliklerinden biri, işletmedeki farklı hiyerarşideki performans göstergeleri arasında açık bir bağlantının varlığıdır. Bu durum, işletmenin bir bütün olarak ortaya konan vizyon doğrultusunda aynı hedeflere doğru ilerlemesini sağlaması açısından önem arz etmektedir. Bu bağlantının nasıl olacağı, Şekil 2'deki piramit yapısında ortaya konmaktadır (Tangen, 2004). Bu yapıda, işletmenin stratejisi; yukarıdan aşağıya hedefler, aşağıdan yukarıya doğru da ölçütler ile bütünleştirilerek işletme faaliyetleri ile ilişkilendirilmektir. Konulan hedefler ise müşteri öncelikleri çerçevesinde belirlenmektedir (Lynch \& Cross, 1992).

Performans piramidinin temel amaçlarından biri, üç ana paydaştan (müşteriler, hissedarlar ve çalışanlar) bilgi sağlayarak işletmenin stratejileri doğrultusunda içsel ve dışsal etkinlik sağlamaktır (Kippenberger, 1996). Bu amaç, işletmenin vizyonu ile başlamakta ve bu aşama piramidin dayanağını oluşturarak işletme hedeflerinin belirlenmesinde yön göstermektedir. İkinci aşamada işletme birimleri, piyasa ve finansal açıdan kısa ve uzun dönemli hedeflerini belirlemektedirler. Üçüncü aşamada birimler, işletme faaliyet sistemleri çerçevesinde müşteri memnuniyeti, esneklik ve verimlilik gibi operasyonel göstergeleri ortaya koymaktadırlar. Son aşamada ise departman ve iş merkezlerinde kalite, teslimat, devir süresi ve israf gibi diğer operasyonel göstergeler belirlenmektedir. Tüm bu operasyonel göstergeler daha üst düzey sonuçlar elde etmek ve işletme stratejisinin başarılı bir şekilde uygulanmasını sağlamak için kilit rol oynamaktadır (Ghalayini \& Noble, 1996).

Performans piramidinde dışsal etkinliğin sağlanmasının odak noktasında müşteri yer almaktadır. Bunun nedeni, müşteri ihtiyaç ve beklentilerinin karşılanması ile oluşacak müşteri memnuniyetinin işletmenin hedef ve stratejilerini gerçekleştirmede itici bir güç olarak yer almasından kaynaklanmaktadır. Piramit yapısından da örnek verilecek olursa; işletmenin ürettiği kaliteli ürün veya hizmetlerin ulaşılabilir ve zamanında teslim kriterlerini sağlaması, müşteri memnuniyetini sağlamaktadır. Bu da işletmenin stratejileri çerçevesinde koyduğu piyasa hedeflerini gerçekleştirmesi anlamına gelmektedir. İ̧̧letme eğer bu koşulları sağlayamaz ise bunun nedenlerini araştırmalı ve müşteri taleplerini göz önüne alarak performans piramidindeki aşamaları güncellemelidir (Lynch \& Cross, 1992).

Performans piramidinin değerlendirilmesi aşamasında dikkat edilmesi gereken noktalardan biri de en düşük seviyede kullanılan bilgilerin temel olarak finansal olmayan; en yüksek seviyede oluşan bilgilerin ise çoğunlukla finansal karakterde olmasıdır. Bu üç unsur (vizyon, finansal ve finansal olmayan bilgiler) bir bütün olarak ele alınarak işletmeler için değer yaratımının değerlendirilmesi yapılabilmektedir (Nilsson \& Stockenstrand, 2015). Sonuç olarak, performans piramidi özellikle kendinden sonra gelen değer bazlı performans ölçüm araçlarının bütünsel bir bakış açısına sahip olmasını sağlamıştır.

\section{Cambridge Performans Ölçüm Çerçevesi (Cambridge Performance Measurement Framework)}

Neely ve arkadaşlarının 1996 yılında, "Getting the Measure of Your Business" isimli çalışmalarında tanımladıkları bir performans yönetim süreci olarak da tanımlanan Cambridge performans ölçüm çerçevesi (Pun \& White, 2005), bu süreci uygulamak adına özellikle müşteri ve paydaş gereksinimlerini temel alan Şekil 3'teki aşamaları sunmaktadır (Taticchi \& Balachandran, 2008).

Çerçevenin temel amacı; işletmeye ait tüm iç-dış ve finansal-finansal olmayan öğelerin tutarlı bir performans ölçüm sistemi çerçevesinde işletmenin stratejisiyle nasıl bütünleştirildiğini göstermektir. Çerçeve, göstergeler arasında bir dengeyi kurmayı amaçlarken gereksiz göstergelerin belirlenmesine de yardımcı olma amacındadır (U. S. Bititci, 2015). 


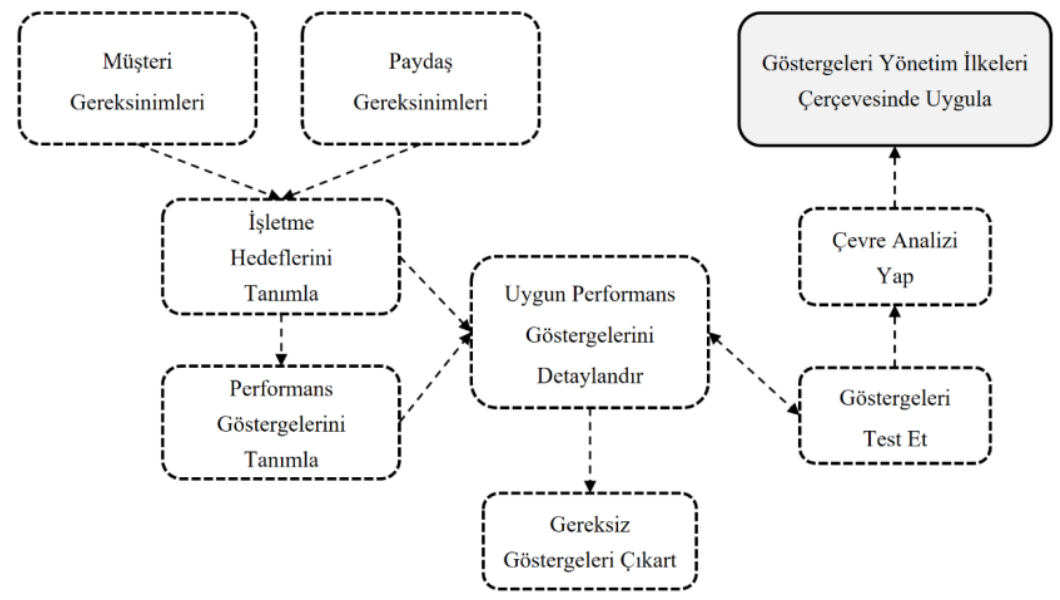

Şekil 3. Cambridge performans ölçüm çerçevesi Kaynak: Umit S. Bititci. (2015).

Cambridge performans ölçüm çerçevesinin, ortaya koyduğu süreçteki en büyük destekçisi ve çıktısı karşılıklı etkileşim içinde olduğu işletme stratejisidir. Bu etkileşimde; işletme stratejisi uygulanacak performans ölçümüne yön vermekte; doğru göstergeler yardımı ile uygulanan performans ölçüm süreci de stratejik hedeflere ulaşmaya katkı sağlamaktadır. Böylece her iki unsur birbirine tamamlamakta ve desteklemektedir (Neely, Bourne, Mills, Platts, \& Richards, 2002). Cambridge performans ölçüm çerçevesi sürecinde önemli bir yere sahip olan performans göstergeleri ile ilgili cevaplanması gereken sorular şunlardır (Mills, Platts, Neely, Richards, \& Bourne, 2002):

$\checkmark$ Göstergelerin kaydını kimleri nasıl tutacak?

$\checkmark$ Göstergelerden sorumlu personeller kimler olacak?

$\checkmark$ Göstergeler hangi birimlerde, departmanlarda uygulanacak?

$\checkmark$ Göstergelerin gelişimi nasıl izlenecek?

$\checkmark$ Göstergeler ve sonuçları ile ilgili geri dönüşler nasıl sağlanacak?

Göstergeler hakkında sorulan sorulara verilen cevaplar, çerçevenin sürdürülebilirliği açısından önem arz etmektedir. Bir performans göstergesi uygulandıktan sonra gerçekleşen kısa vadeli olumlu gelişmeler her zaman sürdürülebilir olmayabilir. O yüzden de göstergeler ile ilgili yapılan analizlerde sağlanan geri dönüşler, işletmenin ilgili birimi tarafından iyi bir şekilde yorumlanmalı ve Cambridge performans ölçüm çerçevesi bu doğrultuda güncellenmelidir. Ancak bunlar yapıldığı takdirde uzun vadeli katkı ve sürdürülebilir gelişim sağlanabilmektedir (Mills, Platts, Bourne, \& Richards, 2002). Sonuç olarak, çerçeve özellikle performans ölçüm sürecinin değerlendirilmesi (sorumlular, uygulayıcılar, geri bildirimler, vb.) konusunda kendinden sonra gelen ölçüm yöntemlerine önemli bir rehberlik sağlamıştır.

\section{Sonuç}

İ̧̧letmelerin içinde bulundukları konumu sürdürülebilir ya da daha iyi hale getirebilmeleri için faaliyetleri hakkında geri bildirim almaları ve insan kaynakları, müşteri, çevre gibi sahip oldukları tüm unsurlara ait bilgileri değer yaratııı bir çerçevede dikkate almaları gerekmektedir. İşletmelerin faaliyetlerine ilişkin söz konusu geri bildirim, yıllardır ve halihazırda işletmenin finansal verilerinden hareketle geleneksel performans ölçüm yöntemleri ile sağlanmaktadır. Ancak yaşanan çeşitli değişimler ve gelişmeler hem işletmelerin hem de işletme paydaşlarının bilgi taleplerinin değişmesine sebep olmuştur. Bu noktada finansal olmayan unsurları da dikkate alan değer bazlı performans ölçümleri ortaya çıkmış olup günümüze kadar konu hakkında birçok çalışma gerçekleştirilmiştir. Ortaya konan değer bazlı performans ölçüm yöntemlerinden özellikle Dengeli Puan Kartı, Ekonomik Katma Değer, Performans Prizması gibi yöntemler hakkında pek çok akademik çalışma yapılmıştır. Ancak ilgili ölçüm yöntemlerine fikirsel olarak katkı sunan ve Tablo 2'de görülen bazı yöntemler ile ilgili fazla bir çalışma ortaya konmamıştır. Çalışmada bu tespitten hareket edilerek fazla bir uygulama alanı bulunmayan ancak konu hakkında çalışma yapanlar tarafından diğer değer bazlı performans ölçüm yöntemlerine dolaylı katkılar sunduğu ifade edilen üç yöntem incelenmiştir. Performans ölçüm matrisi, çok boyutluluk ve denge konusunda kendinden sonra gelen diğer değer bazlı ölçüm araçlarına önemli katkılar sağlamıştır. Performans piramidi, özellikle ölçüm araçlarının daha bütünsel bir bakış açısı sunması, Cambridge performans ölçüm çerçevesi de ölçüm yöntemlerinin değerlendirilmesi hususunda kendinden sonraki ölçüm araçlarına değer katmıştır. Ilgili yöntemlerin en temel ortak noktası, bu yöntemlerin sunduğu anlayışa getirilen eleştirilerin kapsamlı olarak değerlendirilmesi ile farklı değer bazlı performans ölçüm yöntemlerinin ortaya çıkmış olmasıdır. Çalışmanın bu doğrultuda performans ölçümü ve özellikle de değer bazlı performans ölçümü konusunda çalışma yapacaklara ve ilgililere fayda sunması beklenmektedir.

\section{Kaynakça}

Alfaro, J., Ortiz, A., \& Poler, R. (2007). Performance measurement system for business processes. Production Planning \& Control, 18(8), 641-654. https://doi.org/10.1080/09537280701599772

Bititci, U., Garengo, P., Dörfler, V., \& Nudurupati, S. (2012). Performance measurement: Challenges for tomorrow. International Journal of Management Reviews, 14(3), 305-327. https://doi.org/10.1111/j.1468-2370.2011.00318.x

Bititci, U. S. (2015). Managing Business Performance: The Science and the Art. Chichester: John Wiley \& Sons Inc.

Bourne, M., Mills, J., Wilcox, M., Neely, A., \& Platts, K. (2000). Designing, implementing and updating performance measurement systems. International Journal of Operations \& Production Management, 20(7), 754-771.

Bourne, M., Neely, A., Mills, J., \& Platts, K. (2003). Implementing performance measurement systems: a literature review. International Journal Business Performance Management, 5(1), 1-24.

Burgess, T. F., Ong, T. S., \& Shaw, N. E. (2007). Traditional or contemporary? The prevalence of performance measurement system types. International Journal of Productivity and Performance Management, 56(7), 583-602. https://doi.org/10.1108/17410400710823633

Çakır, S., \& Perçin, S. (2013). Çok kriterli karar verme teknikleriyle lojistik firmalarında performans ölçümü. Ege Akademik Bakış, 13(4), 449-459.

Cavlak, H. (2019). Geleneksel, değer bazlı ve alternatif performans ölçütlerinin uluslararası finansal raporlama standartları ile ilişkisi: Borsa İstanbul'da bir uygulama. (Yayımlanmamış Doktora Tezi). Marmara Üniversitesi/Sosyal Bilimler Enstitüsü, İstanbul.

Cross, K. F., \& Lynch, R. L. (1988). The "SMART" way to define and sustain success. National Productivity Review, 8(1), 23-33.

Daft, R. L. (2010). Organization theory and design. Mason: South-Western, Cengage Learning.

Erasmus, P. (2008). Value based financial performance measures: An evaluation of relative and incremental information content. Corporate Ownership \& Control, 6(1), 66-77.

Franco-Santos, M., Lucianetti, L., \& Bourne, M. (2012). Contemporary performance measurement systems: A review of their consequences and a framework for research. Management Accounting Research, 23(2), 79-119. https://doi.org/10.1016/j.mar.2012.04.001

Ghalayini, A. M., \& Noble, J. S. (1996). The changing basis of performance measurement. International Journal of Operations \& Production Management, 16(8), 
63-80. https://doi.org/10.1108/01443579610125787

Ghalayini, A. M., Noble, J. S., \& Crowe, T. J. (1997). An integrated dynamic performance measurement system for improving manufacturing competitiveness. International Journal of Production Economics, (48), 207-225.

Işığıı̧ok, E. (2008). Performans ölçümü, yönetimi ve istatistiksel analizi. Ekonometri ve İstatistik, (7), 1-23.

Keegan, D. P., Eiler, R. G., \& Jones, C. R. (1989). Are your performance measures obsolete? Management Accounting, 70(12), 45-50.

Kippenberger, T. (1996). The performance pyramid. The Antidote, 1(1), 10-11. https://doi.org/10.1108/EUM0000000006389

Koller, T. (1994). What is value-based management? The McKinsey Quarterly, (3), 87-101.

Lynch, R. L., \& Cross, K. F. (1992). Measure Up! Yardsticks for Continuous Improvement. Cambridge: Blackwell Publishers.

Martin, R. (1997). Do we practise quality principles in the performance measurement of critical success factors? Total Quality Management, 8(6), 429-444. https://doi.org/10.1080/0954412979433

Mills, J., Platts, K., Bourne, M., \& Richards, H. (2002). Strategy and Performance: Competing through Competences. Cambridge: Cambridge University Press.

Mills, J., Platts, K., Neely, A., Richards, H., \& Bourne, M. (2002). Strategy and Performance: Creating a Winning Business Formula. Cambridge: Cambridge University Press.

Neely, A., Bourne, M., Mills, J., Platts, K., \& Richards, H. (2002). Strategy and Performance: Getting the Measure of Your Business. Cambridge: Cambridge University Press.

Neely, A., Gregory, M., \& Platts, K. (1995). Performance measurement system design. International Journal of Operations \& Production Management, 15(4), 80-116. https://doi.org/10.1108/01443579510083622

Neely, A., Mills, J., Platts, K., Richards, H., Gregory, M., Bourne, M., \& Kennerley, M. (2000). Performance measurement system design: developing and testing a process-based approach. International Journal of Operations \& Production Management, 20(10), 1119-1145. https://doi.org/10.1108/01443570010343708

Nilsson, F., \& Stockenstrand, A.-K. (2015). Financial Accounting and Management Control. Cham: Springer International Publishing. https://doi.org/10.1007/978-3-319-13782-7

Otley, D. (2007). Accounting Performance Measurement: A Review of Its Purposes and Practices. içinde Business Performance Measurement: Unifying Theory and Integrating Practice. Cambridge: Cambridge University Press.

Parker, C. (2000). Performance measurement. Work Study (MCB University Press), 49(2), 63-66. https://doi.org/10.1108/00438020010311197

Pidun, T., \& Felden, C. (2011). Limitations of Performance Measurement Systems based on Key Performance Indicators. içinde Proceedings of the Seventeenth Americas Conference on Information Systems. Detroit: AIS Electronic Library (AISeL).

Pun, K. F., \& White, A. S. (2005). A performance measurement paradigm for integrating strategy formulation: a review of systems and frameworks. International Journal of Management Reviews, 7(1), 49-71.

Robson, I. (2004). From process measurement to performance improvement. Business Process Management Journal, 10(5), 510-521. https://doi.org/10.1108/14637150410559199

Striteska, M., \& Spickova, M. (2012). Review and comparison of performance measurement systems. The Journal of Organizational Management Studies, 113. https://doi.org/10.5171/2012.114900

Tangen, S. (2004). Performance measurement: from philosophy to practice. International Journal of Productivity and Performance Management, 53(8), 726737. https://doi.org/10.1108/17410400410569134

Taticchi, P., \& Balachandran, K. R. (2008). Forward performance measurement and management integrated frameworks. International Journal of Accounting \& Information Management, 16(2), 140-154. https://doi.org/10.1108/18347640810913807

van Veen-Dirks, P. (2010). Different uses of performance measures: The evaluation versus reward of production managers. Accounting, Organizations and Society, 35(2), 141-164. https://doi.org/10.1016/j.aos.2009.02.002

Watts, T., \& McNair-Connolly, C. J. (2012). New performance measurement and management control systems. Journal of Applied Accounting Research, 13(3), 226-241. https://doi.org/10.1108/09675421211281308

Whiting, E. (1986). A guide to business performance measurements. London: Palgrave Macmillan UK. https://doi.org/10.1007/978-1-349-07472-3

Yadav, N., \& Sagar, M. (2013). Performance measurement and management frameworks. Business Process Management Journal, 19(6), 947-971. https://doi.org/10.1108/BPMJ-01-2013-0003

Yüreğir, O. H., \& Nakıboğlu, G. (2007). Performans ölçümü ve ölçüm sistemleri: genel bir bakış. Çukurova Üniversitesi Sosyal Bilimler Dergisi, 16(2), 545-562.

Zsido, K. E. (2015). Historical Overview of the Literature on Business Performance Measurement from the Beginning to the Present. Applied Studies in Agribusiness and Commerce, 9(3), 39-46. https://doi.org/10.19041/APSTRACT/2015/3/6 